\title{
"Let's make lots of money". The determinants of performance in the recorded music sector
}

\author{
Juan D. Montoro-Pons \\ Departamento de Economía Aplicada \\ Universitat de València \\ Manuel Cuadrado-García \\ Departamento de Comercialización e Investigación de Mercados \\ Universitat de València \\ January 2017
}

\begin{abstract}
This research analyzes the performance of 467 record labels in 8 European countries over a period of 13 years (2003-2015). The main goal is to explain a relative measure of profitability in terms of observed variables, although the nature of the dataset also allows us to include non-observed firm and country effects. To this end alternative models are estimated and three main research questions are tested, namely: (1) the effect of the dual structure of the recorded music market, in which a competitive segment and an oligopoly coexist; (2) the extent and source of the volatility of profits in record labels; and (3) the non-linear impact of size on performance.
\end{abstract}




\section{Introduction}

The interest of researchers in the field of the economics of music has been unbalanced. As Cameron (2016) notes in recent a survey on the state of this field, while many empirical studies on recorded music have analyzed consumers and their motivations, fewer have focused on the supply side of the market and, to the best of our knowledge, none on firms financial performance.

A significant amount of research in the field is due to the appeal of the digitization process and its consequences for the production, marketing, distribution and consumption of recorded music. And yet profits, as a measure of how the sector has performed under this changing technological landscape, have been mainly absent from this debate. This research aims at filling this gap by analyzing the performance of a sample of 467 record labels in 8 European countries. We do so by estimating an econometric model to identify the main determinants of profits and formulate and test hypotheses on the impact on profits of the way the industry is organized.

Our research is related to the literature on the supply of recorded music (in the general context of the cultural industries) and the strategies record labels implement. The cultural industries rely on the unlimited pool of talent and ideas from creators and artists to produce contents that can be marketed. Selecting and producing a constant flow of cultural products is key in a market that depends on products with a short life cycle and a low probability of breaking even. One key function of organizations in the cultural industries is their role as intermediaries or gatekeepers. As Hirsch (1972) points out, firms select the subset of cultural output from artists that will reach consumers, a role that stems from the uncertainty that surrounds cultural production. Cultural organizations address this uncertainty by enforcing links at different points of the industrys value chain, overproduction and promotion.

Several authors relate this selection process and its results to innovation (to be understood as product differentiation innovation, i.e. the release of new artists and the emergence and stabilization of new genres), how it takes place and the associated uncertainty, the risk-reducing effect of a diversified 
portfolio of recordings, and how these features are affected by the way the industry is organised. Baker (1991) shows that market structure is the key to understanding the number of releases of a record label. The author develops a theoretical model of profit maximization and shows that the risk-reducing effects of diversification are exhausted after a relatively small number of releases (in relation to the total market for titles) which may suggest an upper-limit to the advantages of a diversified catalog.

The increasing concentration of the recorded music industry and its impact on market outcomes have been the main topic of several papers. Peterson and Berger (1975) link innovation and diversity in popular music to market structure, putting forward the hypothesis of increasing homogenization and standardization as concentration within the industry increases. This cultural homogenization has been revisited by various authors, such as Lopes (1992), who claims that, despite the "effective unchallenged oligopolistic control" of the industry, innovations and diversity are common because of a reliance on independent producers - the open system or decentralized production hypothesis-. More recently Dowd (2004) combining covariates that capture market concentration, decentralized production and their interactions in the same model, concludes that both hypotheses - cultural homogeneity and decentralized production - are statistically significant when explaining new acts and recording firms using data from Billboard charts from 1940 to 1990.

Discussion of market concentration and innovation emphasizes the structural duality of the industry, in which many small independent labels (consistently identified as more active at product differentiation innovation and at cultivating niche markets) compete alongside with much larger integrated firms or majors. Several authors have discussed this point. Without being exhaustive, Hesmondhalgh (1998) discusses reputation effects in independent dance labels in Britain; Gander and Rieple (2004) analyze the dual structure of the industry, the specific assets that majors and independents hold and how those assets affect how innovations take place and how they are exploited; Strachan (2007) analyzes the practice of micro-independent labels and the impact on the mainstream music industry. Innovation, market structure and gatekeeping is discussed in Ordanini (2006) who provides an 
empirical analysis of the different roles that majors and independents play in the sector, and how this duality affects the way new cultural products reach consumers. The author identifies a direct model (majors sign artists with no prior experience in the industry) and an agency model (majors exploit innovations developed by independent labels). In this scheme, independent labels are innovators due to their strengths in identifying artists that might succeed based on their better knowledge of local repertoire, exploitation of niche markets and the artistic background of their managers. Evidence from sales charts shows differentiated patterns of commercial success for the different selection models.

The supply of innovations and record label performance is analyzed in Burke (1996) using charts and market share in single and album markets, while Hendricks and Sorensen (2009) discuss product discovery when information constraints are in place and how strategies to deal with these affect innovation, as record labels might be under-investing in narrowly defined niche markets. Bourreau et al. (2012) analyze the management strategies that have emerged as a response to digitization. The authors identify alternative value creation and capture mechanisms that define business models in the recorded music industry, and suggest a big bang of managerial innovations through different "experimentation paths", which can be successfully managed by imitating successful models or by smaller more flexible labels. More recently, Bourreau et al. (2013) survey 151 French record labels in an attempt to test the long-tail hypothesis by estimating two specifications for creative output (number of new releases) and commercial output (sales). The authors find that digitization leads to greater creative output but does not improve sales. Interestingly, commercial output, a profit or performancerelated variable, is found to be positively related to number of employees and catalog size, both of which are related to firm size.

The above discussion shows that the recorded music industry has been analyzed from alternative perspectives, but no research analyzing profits and their determinants has been undertaken. This paper contributes to the literature in the economics of music in two ways. First, it analyzes and explains profits in terms of firm and market-specific variables, providing further insight into the supply of the recorded music industry and the 
determinants of performance. Specifically, it takes into account the organization of the industry and how its dual structure (majors/independents) has a non-negligible impact in the performance of record labels. Second, it puts forward a framework in which unobserved heterogeneity across firms and markets is explicitly modeled, allowing us to interpret the breakdown of unexplained differences in profits in terms of: (i) transitory shocks (temporary annual increases or decreases in performance due to greater or lesser success of the normal operation of the firm which must be linked to its catalog of releases), (ii) permanent firm features (endowment or lack of resources specific to the firm, such as managerial practices or organizational structures), and (iii) market conditions (the institutional environment in which record labels operate).

In so doing, a model has been estimated using public financial information. We gather data on 467 record labels in eight European countries (Austria, Belgium, France, Italy, Norway, Spain, Sweden and the UK) over a period of 13 years (2003 to 2015). Taking into account that data are longitudinal, that is, measurements for different years for each record label, a panel data approach has been used. Additionally, as firms are clustered into countries, a three-level hierarchical model has also been tested. Hypotheses are posited on the role of record label size, and the specific structure of the industry in explaining profits. The paper is organized as follows. Firstly, we introduce the empirically testable hypotheses. Next, we describe the dataset and summarize its most outstanding features. Then, we present the estimation strategy, its results and a discussion of the findings. Finally, the last section concludes.

\section{Research hypotheses}

The empirical literature on the determinants of profits - examples are McGahan (1999), McGahan and Porter (1999), Goddard et al. (2005), Goddard et al. (2009) and Bou and Satorra (2007) to mention just a few- provides two primary lines of research with regards to the modeling of a firm's performance. On the one hand, the industrial economics perspective identifies profits as the outcome of industry features such as barriers due to costs, 
regulations, concentration, among others, that limit or prevent competition altogether. Different market structures explain differences in profits between industries. Empirical studies aimed at identifying between-industry differences use samples of firms from different sectors in order to estimate the effect of these barriers.

On the other hand, the strategic management literature focuses on the assets that are specific to the firm and that may explain performance. These could be tangible or intangible resources, such as organizational structures or management practices to mention only two. This strand of the literature aims at explaining the observed variability in profits at industry level, where differences in performance are the outcome of between-firm differences. It is worth noting that both analyses need not be mutually exclusive and indeed they are jointly considered as complementary explanations of performance.

Although the present research, being focused on the recorded music industry, lacks a between-industry analysis, the industrys dual market structure - an oligopoly, the majors, catering for the largest chunk of the market plus a more diverse and competitive segment, the independent labels, composed of many smaller firms - permits the testing of hypotheses on industry organization as a source of profits.

In this context, we propose a model of the financial performance of record labels. Let $y_{i j t}$ be profits for firm $i$ in period $t$. We use the subscript $j$ to account for institutional and economic differences at country level that might have an impact on performance. Then we make profits depend on:

$$
y_{i j t}=f\left(\mathrm{MAJOR}_{i j t}, \mathrm{SIZE}_{i j t}, \mathrm{FIN}_{i j t}, \operatorname{CONCENTRATION}_{j t}\right)
$$

In expression (1) we formulate a model for record label profits that depends on type of record company (major or independent) -MAJOR-, firm size - SIZE - , the firms financial position and balance sheet structure FIN-, and market concentration - CONCENTRATION. On that basis, we posit and discuss hypotheses on the impact of the structure of the industry and the extent of the effect of size on profits 


\subsection{The organization of the recording industry}

The model includes the distinction between majors and independent record labels to account for the effect on profits of the organization of the recorded music industry. When dealing with the supply of recorded music, the literature consistently singles out its two-tier structure - the distinction between majors and independent labels - and its impact from an organizational point of view.

The three majors (Sony, Warner and Universal) are part of entertainment and media multinational corporations and as such they have unrivaled financial clout and are responsible for most commercially successful artists, albums and songs. In terms of market share, according to the Worldwide Independent Network Market Report ${ }^{1}$ majors account for roughly $62 \%$ of the global market. This share is even greater in European markets where it ranges between $80-90 \%$. One would expect this disparity in market clout and in the success of their respective portfolios of artists to lead to differences in performance.

While there are size differences between independent and major record labels, the different performances of majors and independents cannot, however, be strictly a matter of size. Some cost advantages are independent of scale, such as those related to experience and knowledge of the market, access to a network of resources and expertise. As long as independent labels lack access to these specific resources they will find themselves at a disadvantage.

There are also differences in business and management styles as well as institutional arrangements with an economic impact that tend to be different in majors and independents. Such differences include contractual relations with artists and bands, or the ownership of sound recordings which impacts on assets and back catalog, ${ }^{2}$ to mention but two. It has been argued elsewhere - see for instance Gander and Rieple (2004) or Tschmuck (2012) that most music innovations take place in the independents labels and once these catch on they are exploited by majors with the financial clout and

\footnotetext{
${ }^{1}$ See http://winformusic.org/wintel/.

${ }^{2}$ While major labels usually retain the copyright on the sound recording of an act, independent labels do not.
} 
managerial resources to market them profitably. Thus artists backed by the financial muscle and network connections of majors are on a faster track to success (see Ordanini, 2006).

In short, and consistently with the above observations, majors can be expected to have a performance premium. Therefore:

H1 There is a positive majors-effect on profits.

Additionally, the more open approach of independent record labels towards innovation and musical diversity could also be linked to a greater assumption of risks. Whether this innovative behavior is reflected in performance is open to discussion. Less risk averse independent labels could exhibit a larger observed variability in profits. It is, however, true that in a market so dependent on a continuous flow of new releases (few of which break even) the size of a firm's catalog, that is, its portfolio, is important and by enlarging and diversifying its portfolio a firm can mitigate risk. Both the fewer number of releases and the smaller back catalog as well as the concentration in specific segments of the market may explain a larger than average observed variability in profits. Therefore:

H2 Independent record labels exhibit greater variability of profits than majors.

In the discussion section we seek a consistent explanation for the source of this variability.

\subsection{The role of size}

In line with the aforementioned empirical research on profits, we expect an impact of firm size on performance. The dual structure of the industry imperfectly correlates with the size of recorded music labels. While most majors are significantly larger than independent record labels — mainly small and medium-sized enterprises - there is wide diversity among the independents.

Since the mid-sixties (see Tschmuck, 2012) the development of the music industry has been characterized by a process of market concentration. 
Either through horizontal mergers or through the acquisition of competitors, the major players in the industry have become bigger both in terms of catalog, market share and assets. The extent to which this generates economies of scale is debatable, as new digital technologies have drastically reduced production costs for record labels and marketing possibilities have been enhanced by the Internet and social networks. Nonetheless there may well be economies of scope from managing an increasing catalog. The question is at what point are these scale and scope economies (that we relate to size) exhausted.

To estimate the expected effect of size on profits we need first to have an operational definition of size. In this respect we stick to the convention used in the finance literature and resort to total assets as the measure of the size of a firm. We expect the volume of total assets to correlate with a record labels catalog and its financial and other key resources in the production and marketing of music.

A larger size that leads to the achievement of greater efficiencies will expand profits. However, for moderate scale advantages and if the scope of production is exhausted for a certain catalog size, then diseconomies might kick in due to the greater complexity of managing larger organizations. In this case an inverse U-shaped effect of size on profits could be expected, leading to a non-linear relationship between profits and total assets. We formulate this argument with $\mathbf{H 3}$ :

H3 The relation between profits and size is non-linear (profits increase up to a given size and decrease thereafter).

\section{The dataset}

\subsection{Sample selection}

To test H1-H3 a sample of financial data for recorded music firms was selected from Amadeus, a database of comparable financial information for public and private companies across Europe compiled by Bureau van Dijk. The dataset covers over 19 million companies in 43 European countries. Amadeus collects and normalizes the data from information providers, which 
in most cases are national registries where audited annual accounts are filed. Normalization to a standard format makes the financial information comparable across countries. It should be noted that Regulation 1606/2002 of the European Parliament and the European Council on the application of international accounting standards has led to a greater convergence of accounting standards in Europe.

Unconsolidated financial data were gathered for record labels in 8 European countries: Austria, Belgium, France, Italy, Norway, Spain, Sweden and the UK. The choice of countries was based on the availability of the relevant data. As financial information disclosure requirements differ from country to country, only those that offered a reasonable and comparable amount of information were chosen. Overall these countries represent $34 \%$ of the recorded music business in the European region, as reported by IFPI. ${ }^{3}$

The selection of record labels was based on the identification of firms whose main activity is recorded music. The eligibility criterion was the membership list of the International Federation of the Phonographic Industry (IFPI), the main body representing the sector in the eight target countries. This list includes majors and most independent companies. The dataset was enlarged in a second round using information on members of the Independent Music Companies Association (IMPALA) that are not members of IFPI, in all cases smaller independent firms or micro-labels. Overall we obtained information for a panel of 467 record labels over the period from 2003 to 2015 . Note that the panel is unbalanced, as values for specific variables are not available for all years/firms. This is specially so with variables such as number of employees and operating revenue. Below we outline the description of the variables employed in the analysis.

\subsection{Dependent variables}

Performance is measured through a relative measure of profits before taxes. For every firm in the database return on total assets (ROA) has been collected. ROA, defined as the ratio of profits/losses before taxes over total assets, is the most widely used measure of performance in the empirical

\footnotetext{
${ }^{3}$ See SGAE (2012).
} 
literature on the determinants of profits.

Additionally, and as a robustness check, we use a binary qualitative measure (profits/losses) in the modeling strategy. The advantage of such a variable is that it is independent of any measure of size.

\subsection{Explanatory variables}

For each firm in the dataset, the following information is gathered:

1. Country of the firm.

2. Number of employees.

3. Operating revenue.

4. Total assets as per the balance sheet.

5. Total fixed assets

6. Total intangible fixed assets.

7. Financial ratios: liquidity and gearing ratio.

With this information the following explanatory variables are produced.

MAJOR: We classify the record labels in the sample with a dummy variable that takes value 1 if it is a major and 0 otherwise. Major firms are identified based on their global ultimate owner (GUO). GUO of majors were: Vivendi (owner of Universal and other labels such as A\&M, Capitol or Virgin to cite some), Sony Corporation (owner of Sony music and labels such as Arista, Columbia, Epic and CBS), AI Entertainment Holdings LLC (owner of Warner Music Group, Sire and Parlophone among others) and Citigroup Inc. (owner of EMI until 2012, when parts of its business were sold to Universal). Based on this classification, out of 467 record labels, 66 were classified as majors (roughly $14 \%$ of the sample). Note that this includes not only the four majors, ${ }^{4}$ but also sub-labels and subsidiaries that operate autonomously. We expect being a major to have a positive impact on profits, in accordance with $\mathrm{H} 1$

\footnotetext{
${ }^{4}$ Given the time span of the sample, we still include EMI as a separate firm.
} 
OWNERSHIP: An independence indicator has been used. This indicator is provided in the database and has been used to identify the degree of independence of a company with regard to its shareholders. On that basis we built a dummy variable that takes value 1 when there is no shareholder with ownership percentage greater than $50 \%$ and 0 otherwise. We incorporate this covariate to evaluate if and how the ownership structure of a firm affects its performance. The financial literature relates increasing concentration in ownership to a reduction in the potential extent of agency problems and, therefore, to an incentive effect on performance

TOTALASSETS: The book value of total assets (and its square) is used to account for the size of record labels. We aim at identifying efficiency advantages related to size and whether they are exhausted at some point (H3).

EMPLOYEE: We also use the total number of employees of a record label as a proxy for its size. There are different ways in which the size of a firm can be approached: total assets, sales, value added or number of employees are commonly used measures. Assets stress the technological aspects of production (namely scale and scope economies). However, from an organizational standpoint (how hierarchies and complexity play a role in performance) the number of employees can be an alternative and suitable measure of size.

RATIOFIXED: The ratio of fixed assets to total assets is used as a measure of the relative relevance of plant, equipment and other infrastructure for the record label. Digital technologies have drastically transformed the landscape in which record labels operate, and in particular, depreciate the value of assets that were once key to success when the physical production, distribution and marketing model was prevalent. CD pressing plants, warehousing or distribution networks become irrelevant when the business model changes to one dependent on the delivery of digitized information. From discussions with members of the industry it became apparent that embracing the digital business model has gone hand in hand with a process of shedding fixed assets that could otherwise hinder record label profitability.

RATIOINTANGIBLE: The ratio of intangible assets over total assets. Fixed intangible assets — not categorized as fixed assets - are mainly copyrights on sound recordings. This could be considered as a proxy for the relative size 
of a record labels catalog, although there can be stark differences between labels depending on contractual relations with performers and who holds the rights to sound recordings. A larger share of intangible assets over total assets could have a positive effect on performance, as the label focuses on revenue-generating activities.

LIQUIDITYRATIO: The liquidity ratio is the ratio of current assets (net of stocks) to current liabilities. It measures the ability of a company to meet its short-term debt obligations, but can be interpreted as an indicator of managerial conservatism or risk-aversion. Empirical studies in the literature show a positive impact on profits.

GEARINGRATIO: The fraction of non-current liabilities plus loans to shareholder funds is the gearing ratio. It is a measure of financial leverage and, hence, of the financial risk a company takes. Studies in the literature find a negative impact on profits

All of the above capture firm-specific features. We also include a marketlevel variable to grasp differences in countries due to market conditions. The Herfindahl- Hirschman Index (HHI) provides a measure of the concentration of the market in which a firm operates, and it is calculated using information on the market share: $\sum_{1}^{n} s_{i j}^{2}$, with $s_{i j}$ being the market share of firm $i$ in market $j$. We use the concentration index as a measure of the competitive conditions in a market, the larger the index the more concentrated the market. All else being equal, we expect profits to increase with concentration.

\subsection{Descriptive statistics on the sample}

Table 1 shows average data on profits, market and firm size by country. It can be seen that the average firm in the sample has roughly an operating revenue of 12 million euros, assets valued at 22 million and 28 employees, and an average return on assets equal to $2.77 \%$. However the heterogeneity of the music industry is obvious from the diversity of results at country level. Table 1 reveals that firms in different countries perform differently: ROA ranges from $-1.10 \%$ in Spain to $11.81 \%$ in Austria. It is important to remark that these are rough averages, that is, unweighted averages over firms and years, and as such do not discriminate between firms. In terms of 
size, unsurprisingly, UK and France have the largest record labels per assets and employees, which is also reflected in mean operating revenue. Overall, we see that there is heterogeneity at country level worth analyzing.

The differences between majors and independents become apparent in table 2. Majors are larger in terms of assets (total and fixed), employment and revenue. Profits are also larger on average. In this regard, examination of frequency distributions for profits (using ROA as the measure) shows that:

- The distribution of profits for majors is significantly more concentrated around the mean than that of independents. While the mean for majors is $4.72 \%$, that of independents is $2.31 \%$, with standard deviations of 15.88 and 21.50 respectively. Not only the standard deviation, but also the coefficient of variation is larger for independent labels, which points to greater variability in the independents.

- The first and third quartile in both distributions are $0.62 \%$ and $10.25 \%$ for majors and $-3.81 \%$ and $9.86 \%$ for independents. In other words negative instances are more frequent for independents than for majors. Thus independents show a greater interquartile range, thereby reinforcing the evidence for profits being more scattered in the case of independent record labels.

These two observations are consistent with the risk-reducing effect of a larger portfolio or catalog in the case of majors compared to independent record labels. It would also be consistent with the view of majors being more conservative compared to greater risk-taking by independents. In any case this is simply a descriptive analysis and we need to check whether this variability holds after accounting for other potential sources of variation.

Finally, table 3 includes information on the ownership structure of the sample. The database assigns an independence indicator to each company which determines, when possible, the distribution of shareholders. Based on this information the percentage of companies with a greater ownership spread — no shareholder owning more than 50\% - represent roughly $16.3 \%$ of the sample. 


\section{Modeling performance: a hierarchical model for profits}

\subsection{Econometric model}

The econometric specification of model 1 exploits the longitudinal structure of the data. Two alternative specifications for panel data - a random effects and a fixed effects model - are formulated. In addition, and due to the hierarchical structure of the data - observations on profits over years for firms, with firms clustered in countries - we also explore the adequacy of a three-level model with random effects both at firm and country level.

Let $y_{t j i}$ be profits at period $t$ for firm $\mathrm{j}$ in country $i$. Assume these to be determined by a set of explanatory variables. The econometric model is:

$$
\begin{aligned}
y_{i j t}= & \beta_{0 i j}+\beta_{1} \times \text { HHI }+\beta_{2} \times \text { MAJOR }+\beta_{3} \times \text { OWNERSHIP }+\beta_{4} \times \ln (\text { TOTALSASSETS }) \\
& +\beta_{5} \times \ln (\text { TOTALSASSETS })^{2}+\beta_{6} \times \ln (\text { EMPLOYEES })+\beta_{7} \text { RATIOFIXED } \\
& +\beta_{7} \times \text { RATIOINTANGIBLE }+\beta_{8} \times \text { LIQUIDITY }+\beta_{9} \times \text { GEARING }+\epsilon_{i j t}
\end{aligned}
$$

In expression (2) we take the natural logarithm (base e) of TOTALASSETS and EMPLOYEES. Moreover, the coefficient $\beta_{0 i j}$ includes a fixed intercept for all observations $\left(\beta_{0}\right)$, a specific random intercept for each firm $\left(U_{0 i j}\right)$ and a specific random intercept for each country $\left(U_{0 j}\right)$, such that

$$
\beta_{0 i j}=\beta_{0}+U_{0 i j}+U_{0 j}
$$

In short, expression (3) includes unobserved differences between firms $\left(U_{0 i j}\right)$ and countries $\left(U_{0 j}\right)$ as random variables that shift profits accordingly. Expressions (2)-(3) outline a model in which two sources explain profits:

1. Observed firm and country-related variables. This source of variation is explained by the covariates in (2) and described in section 3.3.

2. Unobserved heterogeneity, that can be split into three components:

(a) Transitory shocks to profitability: $\epsilon_{i j t}$. These are year-to-year unexpected changes in within-firms profits, and can be interpreted as the changes in performance due to greater or lesser success of the normal operation of the firm, a feature that must be linked to its catalog of releases. 
(b) Unobserved firm-specific variation: $U_{0 i j}$. This is attributed to the heterogeneity across firms, and could be assimilated to firmspecific assets or management styles whose availability (or lack thereof) increases (or decreases) a firm's profits. In short, it is a firms permanent trait.

(c) Unobserved country-specific variation: $U_{0 j}$. This can be attributed to the heterogeneity across countries, including traits such as the share of domestic repertoire, its variety and innovativeness, the countrys formal and informal institutions (such as the legal framework and enforcement of property rights) and its culture - see Power and Hallencreutz (2002) - , or general economic conditions. Some geographical aspects can also be related to the performance of firms, such as the spatial structure of production, or the existence of locational variations in creativity or easier accessibility to specific resources that lead to benefits of geographical agglomeration — see Scott (1999).

To sum up, estimating model (2)-(3) it is possible to break up the share of the variability of profits into observed and unobserved factors that can be attributed to geography and the institutional and economic environment and to the endowment of specific assets and/or resources linked to the managerial expertise of record labels. Estimation results provide coefficients for the observed variables and a breakdown of the unexplained variance into withinfirm variability (due to $\epsilon_{i j t}$ ), between-firms variability (due to $U_{0 i j}$ ) and country variability (due to $U_{0 j}$ ). However this comes at a cost, in terms of the more stringent assumptions needed. ${ }^{5}$ We therefore present below two standard approaches to regression with panel data - fixed and random

\footnotetext{
${ }^{5}$ One needs to assume strong exogeneity, and error terms and random effects at both levels being iid. Let $X$ be the set of explanatory variables. Then:

$$
\begin{gathered}
E\left[\epsilon_{i j t} \mid U_{0 i j}, U_{0 j}, X\right]=0 \\
\epsilon_{i j t} \sim\left[0, \sigma_{\epsilon}^{2}\right] \\
U_{0 i j} \mid X, u_{0 i} \sim\left[0, \phi^{2}\right] \\
U_{0 j} \mid X \sim\left[0, \psi^{2}\right]
\end{gathered}
$$
}


effects - and a three-level model and perform specification tests to validate the estimates.

\subsection{Estimation results}

Table 4 shows the results of estimating different econometric specifications of model (2)-(3). Specifically we present estimates for two panel data models - fixed effects (model a) and random effects (model b) - and 3-level hierarchical model estimates (models c, $\mathrm{d}$ and e).

As for the model selection strategy, note that for the panel data regression - model (a) and (b) - a Hausman test fails to reject the null, hence the random effects model (b) is preferred. When comparing the random effects model with a 3-level model a likelihood ratio test supports the latter. Additionally variances at the different levels are significant - except for the variance at country level for model (c) - even though the greatest share of the variability occurs at the within-firm level. Note that specification (c) includes the whole set of covariates while in (d) we drop employees and the ratio of intangible assets which account for the largest share of missing data. Overall model (d) is supported by the data. Furthermore, as a robustness check, specification (e) estimates model (d) dropping major record labels from the sample.

As for the estimated coefficients, four results stand out. Firstly, there is evidence of a significant positive majors-effect. The 3-level models for the full sample of record labels (models $\mathrm{c}$ and $\mathrm{d}$ ) show a positive estimate with a significance level below $10 \%$. Note also that for the non-significant result, the random effects model (b), one can marginally reject a lower tail null hypothesis (p-value less than 10\%). According to these results, being a major record label positively increases performance (measured as return on assets) by roughly $4 \%$, which reveals a performance premium for majors.

Secondly, the financial standing, size, and structure of the balance sheet matter. Here all estimations except for (a) show that the greater the share of fixed assets (over total assets) the lower the profits. This finding appears logical because in the digital realm fixed assets tend to be less relevant and may even hinder growth or the embrace of new business models. Moreover, 
the point estimate for this effect marginally increases over time, as new business models develop. ${ }^{6}$

On the other hand, size, measured by the value of the assets, is significant and empirical evidence supports a non-linear specification. The net effect of total assets describes an inverted U-shape, with a maximum within the sample range which suggests the existence of an optimal size. The number of employees, which can be an additional measure of size and organizational complexity, is found to have a negative effect on profits (non-linearities were rejected), although information on number of employees was missing for $67 \%$ of the sample units. In addition, the leverage of a company not only increases its risk but also reduces its performance, as seen by the coefficient attached to the gearing ratio in all the estimated models.

Thirdly, there is evidence of market concentration differences playing a role in profits. The estimated effect of the HHI concentration index is positive and significant for all models, as expected.

Turning to the market and firm unobserved effects, the estimated models provide a breakdown of the unaccounted variability at each level once we have controlled for observed covariates. Examination of the variance of the estimated random intercepts in models (d) and (e) shows that the amount of variability attached to between-country differences is around $3 \%$ of the total variability. Between-firms variability is $22-24 \%$, while within-firm variability is around $73-74 \%$. The evidence supports unobserved variability at firm level due to transitory shocks to be the main source of unobserved profit variability, although permanent between-firm differences and country level do also play a role.

Finally, a brief comment on the estimation results for the subsample of independent music labels (model e) is in order. The rationale behind this exercise is to check the robustness of the above results when excluding the

\footnotetext{
${ }^{6}$ An anonymous referee suggested us to test for this increasingly negative effect. In so doing, we estimated the model for two subsamples: before and after 2008 (first introduction of Spotify, a music streaming service, in main European markets). The negative effect of the ratio of fixed assets over total assets is larger (and its significance greater) in the second sample, although the large standard error of the pre-2008 estimation yields wide confidence intervals.
} 
biggest players in the recorded music market. Overall, we consider results are quite robust with the above findings: qualitatively the negative effects of fixed assets and leverage, and the nonlinear effect of size are present. As for the relative size of the variances at the three levels no differences in their breakdown are found. Hence one can conclude that there are no large departures in the results for the sub-sample of independent labels from those of the full sample.

\subsection{Discussion of the results}

We now assess the likelihood of the hypotheses posited in section 2. First, we have found support for hypothesis $\mathbf{H 1}$ on the existence of a positive majorseffect in all the three-level models - table 4, models (c), (d) and (e)-, while evidence has been somewhat weaker in the random effects specification. Consistent explanations with this observed profit premium can be linked to majors having the access to resources and assets to exploit and market the creative process involved in the recording of music, or to managerial skills or specific organizational arrangements. Additionally, this over-performance can also be explained by factors related to the industry structure, such as market power (the ability to push for better economic conditions on digital platforms), direct (through ownership) and indirect links with the promotional value chain of the industry, their financial clout or the profitable exploitation of an enormous back catalog that continues to generate a steady flow of income.

Second, it has been hypothesized (H2) that independent record labels experience higher volatility in profits. While this higher volatility was suggested in the descriptive analysis of the sample, we need to check, after taking into account all other sources of variability, whether independent labels still have a larger variance. To do so we estimate model (d) with two alternative functional forms in which the variability between independents and majors differs because: (1) the permanent component at firm level shows greater variability in the case of independents (variability of the term $U_{0 i j}$ is larger for independent record labels) ; (2) transitory shocks to profitability (error term $\epsilon_{i j t}$ ) show larger variance for independents. The first functional 
form assumes that the random intercept at firm level $U_{0 i j}$ in model (2)-(3) differs between majors and independent labels. Consider this to be the endowment (or lack thereof) of an asset specific to the firm. This setup implies a greater variability in its endowment for independents. The latter assumes heteroskedastic residuals that depend on the type of record label (major or independent) implying that shocks are larger for independents than for majors. It could be interpreted as the variability of the commercial success of a firms portfolio of new releases in a year being larger for independents than for majors.

The results in table 5 provide evidence of different variability in profits that, once modeled as a specific random effect or through heretoskedastic residuals, supports hypothesis H2. ${ }^{7}$ Comparison of both specifications using information criteria - Akaike information criterion (AIC) and Bayes information criterion (BIC) - favors the higher variability of the transitory effect. It has been proposed that this greater variability is due to unobserved traits: a smaller catalog, or independents being less averse to risk or a combination of both could be likely explanations.

To seek for further evidence we have re-estimated the variance parameters in table 5 removing the top and bottom $25 \%$ of the sample in terms of assets. We expect the remaining firms (majors and independents) in this subsample to be more similar not only in size but also in terms of releases and catalog. In short their portfolio will be subject to less variability. We consider that finding no statistically significant differences in variances would be supportive of the smaller catalog explanation as the source of this greater variability. Otherwise both hypotheses would be likely.

Findings still favor the transitory shock hypothesis as the source of the variability, with estimated variances being 197 and 119.5 for independents and majors respectively. The fact that significant differences in volatility persist in this restricted sample makes both explanations (differences in catalog and risk-aversion) consistent with the empirical evidence. In this respect, results are inconclusive.

Third, there is support for a non-linear effect of size on profits (hypothesis

\footnotetext{
${ }^{7}$ As the estimates of the fixed part of the model do not differ from those in model (d) in table 4 , we only report the variance decomposition in table 5 .
} 
H3). Increasing the size of the firm, measured by the total valuation of its assets, increases profits but only up to a point. Figure 1 illustrates the net effect of size on profits, against (the natural log of) total assets for two different estimates in table 4 -models (d) and (e). Interestingly, it can be seen that, independently of the magnitude of the effect, both are maximum at about the same size. The intuition behind the estimates is that increasing the size of a firm will not necessarily lead to higher profits if that firm is already too large, which would be the case of the majors in the sample. In contrast, smaller firms, with most independent firms falling into this category, could benefit from a larger size.

This effect can be illustrated with back of the envelope calculations using the point estimates in table 4 . We calculate the maximum effect of size at a value of the $\log$ of total assets of $7.3-(\mathrm{d})-$ or $7.18-(\mathrm{e})$. Figure 2 shows a box plot of the log of assets for both independents and majors. Based on the estimated size effect, most observations for major record labels would be too large, while the opposite would happen in the case of independents. In this case the estimated size effect could have a practical implication both in terms of the consolidation process that has been taking place among the majors - which, based on the estimated effect, would be a profit decreasing effect - and of the need for smaller independent firms to become larger to gain efficiency.

Finally, the estimates are robust to sample restrictions and alternative econometric specifications. It has been shown that qualitative results hold when we drop majors from the sample. Additionally, and following a referee's suggestion, a time trend was included to account for the collapse of the recorded music market over the period analyzed. As expected, the trend was significant and negative, and there was no change in sign, magnitude or significance of the rest of covariates. ${ }^{8}$ Furthermore, a binary data model was estimated using profit/loss as the dependent variable to provide further evidence on the hypotheses tested, and to re-asses the robustness of the results. The rationale behind this exercise is to avoid the limitations of ROA as a measure of profits. Note that, as ROA is the ratio of profits to

\footnotetext{
${ }^{8}$ However there was some ambiguity as to the preferred model based on information criteria, as BIC and AIC led to contradictory results.
} 
assets, the way a firm manages its assets could lead to different ROA values for the same amount of profit. ${ }^{9}$ Qualitative results hold: data support the random effects specification and we find evidence of a positive majors-effect, a positive effect of HHI, a negative effect of the ratio of fixed assets and the gearing ratio, and a non-linear effect of total assets on the probability of profits. Results are shown in table 6 .

\section{Conclusions}

The present research sheds some new light on the supply side in the recorded music industry, more specifically on the factors that determine the performance of record labels.

First of all, we found that the structure of the recording industry has a significant and consistent effect on profits. In all estimated models, there is evidence of majors overperforming independent labels thereby supporting the hypothesis of a positive majors-effect. This effect, independent of size as it was controlled for in all models, is consistent with the literature in that it can be related to access to specific resources, accumulated knowledge, expertise and connections (especially in the promotional value chain), that enhance the ability to exploit and market successful innovations.

Second, we analyzed the variability of profits within the modeling framework, and found that, after controlling for all the explanatory variables, independents show greater variability. Evidence supports the source of this variability as transitory innovations rather than permanent firm characteristics. It makes sense in a market with a short product life cycle highly dependent on a continuous stream of new products with very uncertain results. In this case the success of the portfolio of new releases determines the performance of the firm, and one can expect profit variability to be influenced by the firms size. The greater catalog and number of releases by majors or more innovative independent record labels are consistent explanations of the observed volatility. At this point, this remains an open question worthy of further research.

\footnotetext{
${ }^{9}$ E.g. ownership of sound recordings is considered an asset, a practice that is not that common for smaller independent firms.
} 
Third, a non-linear size effect has been consistently found. Evidence points to the performance of record labels benefiting from economies of scale and/or scope up to a point. From this we conclude that size plays a role by hindering profits for either too large or too small record labels. Linked to this is the fact that fixed assets, of less value when the business model turns towards the digital distribution of contents, also reduce profitability.

Fourth, though results show that most of the variability in performance comes from within-firm innovations - how well a firm performs in one specific time period which should be attributed to how well its releases fare-, it is also between-firms and to a minor extent country dependent. Firm heterogeneity that can be related to differences in organizational structure or management practices, or the implementation of successful business models explains around $25 \%$ of the total variation in profit between firms. An even smaller percentage (but statistically significant) is related to specific market conditions or between-countries heterogeneity.

Our results have some limitations. It would have been desirable to include more countries and more varied information (beyond purely financial data) to better account for country and firm level variability. This information would have provided additional ways of controlling for firmheterogeneity that at this point is unobserved and therefore mostly included in the random effect at firm level. However, beyond the obvious limitations with the sample due to data availability, the robustness of the findings supports the foregoing analysis of the factors explaining the profitability of record labels and the main conclusions. 


\section{References}

Baker, A. J.(1991). A model of competition and monopoly in the record industry. Journal of Cultural Economics, 15(1):29-53.

Bou, J. C. and A. Satorra(2007). The persistence of abnormal returns at industry and firm levels: Evidence from spain. Strategic Management Journal, 28(7):707-722.

Bourreau, M., M. Gensollen, and F. Moreau(2012). The impact of a radical innovation on business models: Incremental adjustments or big bang? Industry and Innovation, 19(5):415-435.

Bourreau, M., M. Gensollen, F. Moreau, and P. Waelbroeck(2013). selling less of more? the impact of digitization on record companies. Journal of cultural economics, 37(3):327-346.

Burke, A. E.(1996). The dynamics of product differentiation in the british record industry. Journal of Cultural Economics, 20(2):145-164.

Cameron, S.(2016). Past, present and future: music economics at the crossroads. Journal of Cultural Economics, 40(1):1-12.

Dowd, T. J.(2004). Concentration and diversity revisited: production logics and the us mainstream recording market, 1940-1990. Social forces, 82(4):1411-1455.

Gander, J. and A. Rieple(2004). How relevant is transaction cost economics to inter-firm relationships in the music industry? Journal of Cultural Economics, 28(1):57-79.

Goddard, J., M. Tavakoli, and J. O. Wilson(2005). Determinants of profitability in European manufacturing and services: evidence from a dynamic panel model. Applied Financial Economics, 15(18):1269-1282.

Goddard, J., M. Tavakoli, and J. O. Wilson(2009). Sources of variation in firm profitability and growth. Journal of Business Research, 62(4):495508. 
Hendricks, K. and A. Sorensen(2009). Information and the skewness of music sales. Journal of political Economy, 117(2):324-369.

Hesmondhalgh, D.(1998). The british dance music industry: a case study of independent cultural production. British Journal of Sociology, Pp. 234251.

Hirsch, P. M.(1972). Processing fads and fashions: An organization-set analysis of cultural industry systems. American journal of sociology, Pp. 639659.

Lopes, P. D.(1992). Innovation and diversity in the popular music industry, 1969 to 1990. American sociological review, Pp. 56-71.

McGahan, A. M.(1999). The performance of us corporations: 1981-1994. Journal of industrial economics, Pp. 373-398.

McGahan, A. M. and M. E. Porter(1999). The persistence of shocks to profitability. Review of economics and statistics, 81(1):143-153.

Ordanini, A.(2006). Selection models in the music industry: How a prior independent experience may affect chart success. Journal of Cultural Economics, 30(3):183-200.

Peterson, R. A. and D. G. Berger(1975). Cycles in symbol production: The case of popular music. American sociological review, Pp. 158-173.

Power, D. and D. Hallencreutz(2002). Profiting from creativity? the music industry in stockholm, sweden and kingston, jamaica. Environment and Planning A, 34(10):1833-1854.

Scott, A. J.(1999). The us recorded music industry: on the relations between organization, location, and creativity in the cultural economy. Environment and Planning A, 31(11):1965-1984.

SGAE(2012). Anuario SGAE de las artes escénicas, musicales y audiovisuales (Performing arts, music and audiovisual yearbook). Fundacin Autor: http://www.anuariossgae.com/. 
Strachan, R.(2007). Micro-independent record labels in the uk discourse, diy cultural production and the music industry. European Journal of Cultural Studies, 10(2):245-265.

Tschmuck, P.(2012). Creativity and innovation in the music industry. Springer. 
Table 1: Descriptive statistics (i): average roa and main covariates by country and total. (Sales, operating revenue and assets in '000 euros.)

\begin{tabular}{lrrrrr} 
& & & & \multicolumn{2}{c}{ Assets } \\
\cline { 5 - 7 } cntry & ROA & Revenue & Total & Fixed & Employees \\
\hline Austria & 11.81 & $10,053.23$ & $8,760.18$ & $1,529.78$ & 24.59 \\
Belgium & 3.98 & $12,464.77$ & $10,182.86$ & $3,958.51$ & 14.93 \\
Spain & -1.10 & $5,158.52$ & $6,992.68$ & $2,729.65$ & 15.69 \\
France & 1.67 & $19,168.11$ & $35,255.85$ & $20,503.72$ & 51.72 \\
UK & 6.13 & $33,212.28$ & $46,313.82$ & $12,184.76$ & 85.18 \\
Italy & 3.74 & $7,005.67$ & $13,236.15$ & $5,160.34$ & 20.35 \\
Norway & 4.21 & $2,693.26$ & $1,989.17$ & 513.32 & 4.62 \\
Sweden & -0.99 & $2,911.95$ & $3,496.52$ & 475.67 & 5.40 \\
\hline Total & 2.77 & $11,646.23$ & $22,725.78$ & $7,952.99$ & 28.00 \\
\hline
\end{tabular}

Table 2: Descriptive statistics (ii): mean, standard deviation and coefficient of variation of ROA and main covariates by type of record label. (Operating revenue and assets in million euros.)

\begin{tabular}{|c|c|c|c|c|c|c|}
\hline & \multirow[b]{2}{*}{$\mathrm{ROA}$} & \multirow[b]{2}{*}{ Revenue } & \multirow[b]{2}{*}{ Total } & \multicolumn{2}{|c|}{ Assets } & \\
\hline & & & & Fixed & Employees & \\
\hline \multirow{3}{*}{ Indep. } & 2.31 & 3.57 & 3.03 & 0.83 & 12.34 & mean \\
\hline & 21.50 & 1.19 & 9.94 & 4.50 & 28.65 & $\mathrm{sd}$ \\
\hline & 9.29 & 3.35 & 3.28 & 5.39 & 2.32 & $\mathrm{cv}$ \\
\hline \multirow{3}{*}{ Majors } & 4.72 & 45.76 & 132.67 & 47.66 & 94.84 & mean \\
\hline & 15.88 & 77.88 & 395.32 & 160.40 & 152.09 & $\mathrm{sd}$ \\
\hline & 3.37 & 1.70 & 2.98 & 3.37 & 1.60 & $\mathrm{cv}$ \\
\hline
\end{tabular}


Table 3: Distribution of ownership concentration.

\begin{tabular}{lrrr}
\hline Description & Freq. & Percent & Cum. \\
\hline All shareholders $<50 \%$ ownership & 76 & 16.3 & 16.3 \\
At least one shareholder $>50 \%$ ownership & 265 & 56.7 & 73.0 \\
Unknown & 126 & 27.00 & 100.0 \\
Total & 467 & 100 & \\
\hline
\end{tabular}


Table 4: Estimation results. Dependent variable: return on assets (roa).

\begin{tabular}{|c|c|c|c|c|c|}
\hline \multirow[t]{2}{*}{ Model } & (a) & (b) & (c) & (d) & (e) \\
\hline & $\mathrm{FE}$ & $\mathrm{RE}$ & 3-level & 3-level & 3-level \\
\hline \multirow[t]{2}{*}{ MAJOR } & & 4.6849 & $4.0615^{*}$ & $4.8237^{* *}$ & \\
\hline & & $(2.9195)$ & $(2.2345)$ & $(1.8046)$ & \\
\hline \multirow[t]{2}{*}{ OWNERSHIP } & & -1.1087 & -0.3213 & -1.0964 & -1.5833 \\
\hline & & $(2.6327)$ & $(2.0383)$ & $(1.6658)$ & $(1.7664)$ \\
\hline \multirow[t]{2}{*}{ HHI } & $0.0013^{*}$ & $0.0013^{* *}$ & $0.0015^{* *}$ & $0.0013^{* *}$ & $0.0013^{* *}$ \\
\hline & $(0.0007)$ & $(0.0007)$ & $(0.0006)$ & $(0.0005)$ & $(0.0006)$ \\
\hline \multirow[t]{2}{*}{ RATIOFIXED } & -5.2676 & $-5.4511^{*}$ & $-5.4722^{* *}$ & $-8.7446^{* *}$ & $-11.1432^{* *}$ \\
\hline & $(3.6511)$ & $(2.9345)$ & $(2.6870)$ & $(1.9278)$ & $(2.3681)$ \\
\hline \multirow[t]{2}{*}{ RATIOINTANGIBLE } & -3.3191 & -2.5222 & -2.2115 & & \\
\hline & $(5.3546)$ & $(4.4774)$ & $(4.1435)$ & & \\
\hline \multirow[t]{2}{*}{$\operatorname{lnEMPLOYEE~}$} & $-2.5479^{* *}$ & $-2.0487^{* *}$ & $-1.6043^{* *}$ & & \\
\hline & $(0.9819)$ & $(0.7344)$ & $(0.6544)$ & & \\
\hline \multirow[t]{2}{*}{ lnTOTALASSETS } & $9.8393^{* *}$ & $4.8390^{* *}$ & $3.8039^{* *}$ & $4.4500^{* *}$ & $5.5688^{* *}$ \\
\hline & $(3.1275)$ & $(1.7319)$ & $(1.4237)$ & $(0.9957)$ & $(1.4711)$ \\
\hline \multirow[t]{2}{*}{$\operatorname{lnTOTALASSETS}{ }^{2}$} & $-0.4201^{* *}$ & $-0.2268^{* *}$ & $-0.1735^{*}$ & $-0.3047^{* *}$ & $-0.3876^{* *}$ \\
\hline & $(0.1975)$ & $(0.1097)$ & $(0.0893)$ & $(0.0689)$ & $(0.1130)$ \\
\hline \multirow[t]{2}{*}{ LIQUIDITY } & -0.1420 & $-0.1523^{*}$ & $-0.1503^{*}$ & -0.0662 & -0.0740 \\
\hline & $(0.0880)$ & $(0.0801)$ & $(0.0796)$ & $(0.0518)$ & $(0.0601)$ \\
\hline \multirow[t]{2}{*}{ GEARING } & $-0.0160^{* *}$ & $-0.0148^{* *}$ & $-0.0145^{* *}$ & $-0.0156^{* *}$ & $-0.0155^{* *}$ \\
\hline & $(0.0035)$ & $(0.0030)$ & $(0.0029)$ & $(0.0025)$ & $(0.0029)$ \\
\hline \multicolumn{6}{|c|}{ Estimated random effects variances } \\
\hline \multirow[t]{2}{*}{ Country $\left(U_{0 j}\right)$} & & & 3.9860 & $10.0547^{* *}$ & $11.4096^{* *}$ \\
\hline & & & $(4.1405)$ & $(6.8568)$ & $(8.3297)$ \\
\hline \multirow[t]{2}{*}{ Between firms $\left(U_{0 i j}\right)$} & & & $68.33075^{* *}$ & $74.5044^{* *}$ & $77.5674^{* *}$ \\
\hline & & & $(10.7594)$ & $(8.6481)$ & $(10.5785)$ \\
\hline \multirow[t]{2}{*}{ Within firm $\left(\epsilon_{i j t}\right)$} & & & $156.3291^{* *}$ & $226.0947^{* *}$ & $255.8550^{* *}$ \\
\hline & & & $(6.7917)$ & $(6.6215)$ & $(8.3904)$ \\
\hline $\mathrm{N}$ & 1389 & 1389 & 1389 & 2748 & 2226 \\
\hline
\end{tabular}


Table 5: Estimated variances for: (a) a random intercept which differs between major and independent labels (permanent component); (b) heteroskedastic residuals with respect to dummy variable major (transitory shock).

\begin{tabular}{lcl}
\hline & (a) Permanent component & (b) Transitory shock \\
\hline Major & $15.9639^{* *}$ & $105.4263^{* *}$ \\
& $(9.1063)$ & $(6.7851)$ \\
\multirow{2}{*}{ Independent } & $81.0257^{* *}$ & $257.795^{* *}$ \\
& $(10.7971)$ & $(8.4505)$ \\
\hline \multirow{2}{*}{ AIC } & 23128.20 & 23011.57 \\
BIC & 23205.15 & 23088.51 \\
\hline
\end{tabular}


Table 6: Robustness check: estimation of a logit model (dependent variable: profits/losses). Fixed effects (FE) and random effects (RE).

\begin{tabular}{lcccc}
\hline Model & $(\mathrm{a})$ & $(\mathrm{b})$ & $(\mathrm{c})$ & $(\mathrm{d})$ \\
Specification & $\mathrm{FE}$ & $\mathrm{RE}$ & $\mathrm{FE}$ & $\mathrm{RE}$ \\
\hline MAJOR & & 0.5733 & & $1.1348^{* *}$ \\
HHI & & $(0.4540)$ & & $(0.3438)$ \\
& 0.0001 & 0.0001 & 0.0002 & $0.0002^{*}$ \\
OWNERSHIP & $(0.0002)$ & $(0.0001)$ & $(0.0001)$ & $(0.0001)$ \\
& & 0.1617 & & 0.2794 \\
RATIOFIXED & $-2.3243^{* *}$ & $-1.5942^{* *}$ & $-2.3509^{* *}$ & $-1.8805^{* *}$ \\
& $(0.8201)$ & $(0.5338)$ & $(0.4502)$ & $(0.3206)$ \\
RATIOINTANGIBLE & $-2.1427^{*}$ & -1.3224 & & \\
& $(1.2050)$ & $(0.8084)$ & & \\
$\ln ($ EMPLOYEE $)$ & -0.2098 & -0.1116 & & \\
& $(0.2139)$ & $(0.1289)$ & & \\
$\ln$ (TOTALASSETS) & $1.4154^{* *}$ & $0.6556^{* *}$ & $1.2288^{* *}$ & $0.7722^{* *}$ \\
& $(0.6191)$ & $(0.2716)$ & $(0.3607)$ & $(0.1610)$ \\
$\ln (\text { TOTALASSETS })^{2}$ & -0.0481 & -0.0267 & $-0.0545^{* *}$ & $-0.0491^{* *}$ \\
& $(0.0400)$ & $(0.0171)$ & $(0.0272)$ & $(0.0115)$ \\
LIQUIDITY & -0.0156 & -0.0266 & -0.0002 & -0.0034 \\
GEARING & $(0.0201)$ & $(0.0171)$ & $(0.0115)$ & $(0.0090)$ \\
& $-0.0026^{* *}$ & $-0.0023^{* *}$ & $-0.0021^{* *}$ & $-0.0022^{* *}$ \\
& $(0.0007)$ & $(0.0006)$ & $(0.0005)$ & $(0.0004)$ \\
\hline & 911.000 & 1373.000 & 1997.000 & 3162.000 \\
\hline
\end{tabular}

